\title{
TARIFFING OF CONSEQUENTIAL LOSS INSURANCE
}

\author{
Paul Johansen
}

Denmark

I. In the following, consequential losses after fires are considered. A generalisation to consequential losses after other risks is most likely rather trivial.

2. The purpose of this paper is rather asking questions and putting a problem before the readers than presenting solutions. According to our experience, little has been done to seek logical systems or to construct mathematical or physical models in order to study these problems. The volume of business is rapidly growing but it could grow much more if a more reasonable tariffing was made. Many insured with fire insurances hesitate to take out an additional consequential coverage. They can see the need of the coverage, but they will not accept - and rightly - the present market rates. Actuarial colleagues are invited to join in building up suitable models to guide the practical underwriter.

3. The office premium today is most often composed of the following parameters:

a. the premium rate of the corresponding fire insurance

b. the insurance sum, defined e.g. as the expected turnover less variable costs

c. the coverage period, an upper limit of the period in which indemnity can be given. In Denmark, for a period of 12 months the premium of a consequential loss' insurance is normally defined as the insurance sum multiplied by the fire premium +25 per cent.

4. We shall regard various risk situations in order to study the relationship between the fire risk and the consequential loss. The most simple situation is an undertaking where practically spoken only total fire losses will occur. One may think of a fireworks factory or a telephone exchange building. The fireworks factory will burn out physically. After a fire the contents of the telephone building, even if the majority of the materials is at hand, will be worthless because of the corrosion caused by the $P V C$ contents of 
the wires. In the cases mentioned, an outbreaking fire might, of course, be extinguished so early that practically no damage will occur. If the fire, however, exceeds a certain extent, a total loss is likely to follow.

Even if the contents of a building are totally destroyed by a fire, this needs not lead to a very grave damage to the building itself. This is the reason why the consequential loss insurance in our country is most often attached to the fire insurance of the contents.

5. In the risk situation regarded there will be a probability $P$ of the outbreak of a (non trivial) fire. The net premium rate of the fire insurance of the contents therefore is also $P$. The net office premium is $P \times F S, F S$ being the Fire insurance Sum, normally the current value of the contents. In this connection we do not consider the security and administration loading of the risk premium.

Now we presume that the consequential loss sum is defined as the gross profit to be compensated. Let us assume an indemnity period of $M$ months and let CS be the total Consequential loss' Sum.

The risk premium will, of course, depend on the time necessary to get the production resumed. In the example let us estimate the period to $m$ months.

If both the fire outbreak risk and the activity of the business is equally spread over the calendar year, then one may calculate the net premium as

$$
P \times C S \times \frac{m}{M}
$$

If the fire risk is spread but the business is concentrated to a special season, a fire just before that season would imply a total loss while a fire just after the season would bring no consequential loss. In that strange situation our equation might still hold.

In practice an even distribution of the fire risk will not occur. Every undertaking will be especially busy when season is near and the fire risk will concentrate in busy periods. So, in business with typical seasons one must use a weaker reduction than the $m / M$ of our formula.

For food production (other than Christmas puddings) and retail shops a substantial discount will seem reasonable, but not for seaside boarding houses e.g. 
6. Fortunately, total losses will occur only now and then. Normally, a fire will destroy the production system or the goods partially. The proportion between the fire loss and the consequential loss can assume many different values. One may imagine a total loss of a machine or a stock of goods easily replaceable, this will lead to a minor consequential loss only. On the other hand, a rather small fire damage can affect minor but vital parts of the production system which are difficult to rebuild, thus causing a disproportionately big consequential loss.

One may think of a production system composed of several successive processes each in its separate workshop, schematically. expressed as follows:

Raw materials $\rightarrow$ Workshop $\mathrm{I} \rightarrow$ Semi-manufacture $\rightarrow$ Workshop $2 \rightarrow$ Finished goods.

In each workshop we assume for the time being that only a total fire loss can occur. If any fire in one of the two workshops will result in the same consequential loss sum $C S$, the net premium can be expressed like this:

$$
P_{1} \times C S+P_{2} \times C S=\left(P_{1}+P_{2}\right) C S
$$

If furthermore, the fire risks of the two workshops are equal and if the total fire sum is $F S=F S_{1}+F S_{2}$, then the fire net premium will be $P \times F S$ but the net consequential loss' premium $2 \times P \times$ $C S$. It is obvious that if the production line consists of $n$ instead of 2 isolated workshops, this factor 2 must be substituted by an $n$.

7. Now we will look at a quite different production structure, but still under the assumption of total fire losses only. Instead of a successive process we regard a production with a number of parallel columns in each its isolated workshop.

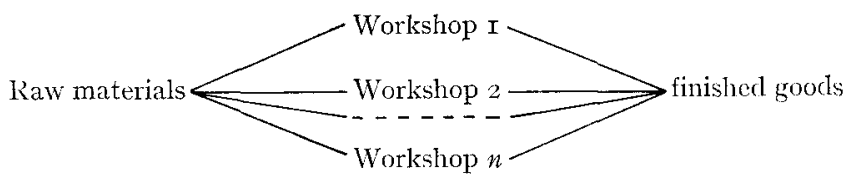

If each individual workshop had its own accounting, with adequate separation of all costs, an independent insurance might be written for each risk. 
We must, however, suppose that both the insurer and the insured would prefer to regard the total risk as a whole. Normally, it would be possible to transfer at least some of the production from a damaged workshop to the others. This would be reasonable only if the extra costs connected with the transfer are less than the consequential loss in itself. If not, nothing economically would be gained.

Under the present assumption of total losses only, it would be possible to calculate the savings in advance. In this risk situation it is therefore quite reasonable to offer a premium discount. The size of this discount depends on the number of parallel workshops and on how strong their ordinary charging is. If the production is programmed so that there is always capacity left, and such a margin will in many cases be desirable from ordinary operational regards, a substantial discount might be appropriate-increasing with the number of workshops.

8. In practice, for larger risks you will find a conglomerate of parallel and chain operations, some of these under one roof, some in separate buildings, e.g.

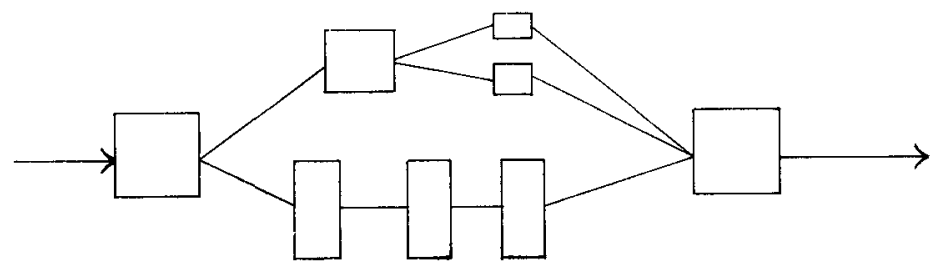

We have the impression that in numerical calculations of this kind one could find a useful paradigm in the theory of electrical resistors, but we have not had an opportunity to follow that path.

9. The situation described in par. 7 assumed that the different workshops were totally isolated so that no fire could spread from one to another. In a more realistic model with two workshops we will assume a partial fireproof separation between the workshops, but with a certain risk $R$ that a fire in one workshop will spread to the other and totally destroy that one too. Still, we do not consider partial damage in one workshop and we assume the same value and the same construction of the two. 
Now, one out of 5 possible events may occur:

I. A fire breaks out in $W_{1}$, destroys that but stops here.

2. A fire in $W_{1}$ infects $W_{2}$ so that both workshops are destroyed.

3. A fire breaks out in $W_{2}$, destroys that but stops here.

4. A fire in $W_{2}$ infects $W_{1}$ so that both workshops are destroyed.

5. No fire breaks out.

The corresponding probabilities are:

$$
P_{1}=P_{3}=P(\mathrm{r}-R) \quad P_{2}=P_{4}=P \times R \quad P_{5}=\mathrm{I}-2 P
$$

and the theoretical discount corresponding to a possible transfer of the production from one workshop to the other will be negatively correlated with the extension risk $R$ like this:

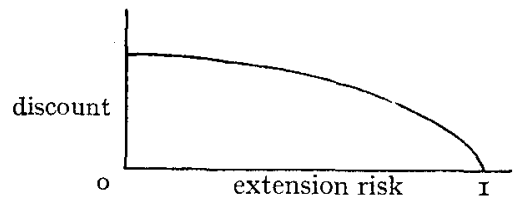

In a still more general situation, the discount rate will vary positively with the chance of transferring the production and negatively with the extension risk.

Io. Our assumption until now was that only total losses could occur. In the practical world, all shades between total losses and zero losses do occur, but logically one might divide the production process into so small units-even one machine can be split into many single gadgets-that only total losses of those single parts could occur. (This would be a similar breaking up process as is used in computer programming). These numerous parts may be combined into thousands of possible loss cases which cannot be overlooked in advance. One must use statistical methods and weigh the different realizations with their respective probabilities.

Ir. It seems reasonable, in order to determine the consequential loss' premium, to start with the fire premium of the business in question. In fire one calculates the office premium as the product of the sum insured and the premium rate. In consequential loss' insurance one must also multiply the fire premium rate by the maximum consequential loss, but this product must be corrected for two reasons. A partial fire loss may involve a relatively large conse- 
quential loss, so that the office premium must be multiplied by an accumulation factor greater than I. On the other hand, a partial fire loss may involve a possible production reorganization so that full production can be maintained with certain extra costs. So the premium can be corrected by a reorganization factor less than $\mathrm{I}$.

The office premium might thus be determined as fire premium rate $\times$ consequential loss' sum $\times$ accumulation factor $\times$ reorganization factor.

A closer study of these factors must be made like you study individual ratemaking for large fire risks. The engineer must estimate the risk of the outbreak and spread of a fire from his inspection on the spot. Then the underwriter from his experience with other fires must estimate the size of the factors in the formula.

I2. We are aware that these remarks in themselves give little news to the experienced underwriter.

Much more is to be done in order to work out realistic models with a few essential and easily estimated parameters.

Here the non-life actuary will naturally collect the technical and statistical information, but we feel that impulses can be gained from various and partly very distant fields. The similarity to electrical engineering has already been mentioned, but the multiplicity spoken about in par. Io, could possibly be attached by the methods of operations' research.

In engineering, the reliability theory has been worked out to study the risk of a breakdown of a production line. The possible causes of such a breakdown are much more general than the fire risk regarded here, ordinary wear and tear has an overwhelming significance. Most likely our transfer problems could be regarded as a special case of reliability theory.

By the way, actuaries should study that theory for a quite different reason also. The random machinery breakdowns and their random repair times correspond to the occurrence of insurance losses and their economic size. The final expression for the probability of a total stop of a complicated production system is quite identical with the classical exponential expression of the probability of ruin of an insurance business.

If it should be inviting to study the reorganization possibilities in detail, we think that also here parallels may be found in other 
fields. In computer science emergency programs have been made for alternative solutions in case a part of the central unit goes on strike and in anatomy minor blood veins will take over the functions of a major vein damaged.

The author wants to thank Mr. Lars Halling, with whom he has discussed the subject and who has given much useful advice on some of the aspects of the paper. 